\title{
Design and Implementation of College Students Information System
}

\section{Based on Internet}

\author{
Guangyu Peng \\ Hunan Communication Polytechnic, Changsha 410132, China \\ mail3@163.com
}

Key words: Internet, Values, University students

\begin{abstract}
This paper focuses on the characteristics of Internet and explores the influence and countermeasures of Internet on the values of our university students. The Internet as an important invention in twentieth century, is affecting everyone's life, especially have an important impact on how to deal with this problem for our college students' value, it becomes an important subject in the present ideological and political education in universities.
\end{abstract}

\section{Introduction}

With the rapid development of science and technology, although the newspaper radio and television and other traditional forms of communication affect our daily life, but the fact cannot be denied, is the Internet as a new communication way and the platform boarded the stage of history, and is playing a role of the Internet which cannot measure the popularization, it changes the distance between people and the world, but also changed the communication environment, which makes the whole world change greatly, especially have an important impact on the values of our university students [1-3]. Values are the criterion of which social members choose their desired goal to evaluate the behavior of things from a variety of potential targets; everyone is a different value orientation in their respective under the guidance of values, to pursue their most valuable thing at present. The emergence of the Internet brought hitherto unknown challenge for our college students. College students are the most active and curious group, so they are of course the Internet enthusiasts and practitioners. Statistical report shows that college students are one of the most active groups on the network $[4,5]$. The Internet culture has the characteristics of openness, freedom, equality, interactive, anonymous and rapid; they brought a lot of influence and impact on contemporary college Students' ideas, values, modes of conduct, especially on the formation of university students' values and establish the far-reaching influence [6]. This is a double effect, both rare opportunities and challenges, so this requires the educators make full use of the unique advantages of the Internet to analyze carefully and find the corresponding measures, to provide effective guidance and education for college students.

\section{Influence of Internet on modern college students' view of value}

The network represents a new and fantastic world for university students, it greatly broaden their horizons, bring convenience and fun to their learning and life, make it easier for them to accept some positive values, but the network is a double-edged sword, it brings positive effect on the formation of the students' values. At the same time, it also has a negative impact and shock quietly estate [7]. 
Concept of opening to the outside world and Westernization of ideology. With the expansion of capitalism and greed looting, the world is linked together, any country, any area, any nation cannot be isolated from the rest of the world and existence. But today's society is no longer to conquer the world through the traditional way, from the original hard conquest to soft conquer, now some capitalist countries through the Internet on our soft conquest. Many capitalist ideas and arguments with the Internet rapidly enter China, thus produced profound effect to the university students' values of our country. The university is the university students' values formation stage, students can easily through the Internet to contact theory of capitalism and culture, so that the students thought are in a deep contradiction, because the Internet is a pluralistic coexistence, on a solution may be in many ways, but in this constant change, different values of fierce collision, they use these public opinion way, aggressively peddled bourgeois individualism, which brings the serious influence on the formation of period values of our college students. They put the Western values of individualism as the base through the Internet, to individual happiness as the overall goal, with individual struggle for realizing ways of ideological indoctrination to us, make the student's self desire expansion, self development as the goal.

The diversified value concept and confused value orientation. A variety of cultural network that produced in different geographical, ethnic, background, breaks the geographical, transportation, media and other restrictions, deepens exchanges and fusion, forms a shared situation of various cultures, which is brought by information globalization process open and diversified, with hitherto unknown the vitality of cultural development, appear the values of pluralism, this is conducive to the students in the humanistic spirit of open, sibilate various cultures and different values, thus establishing tend to be more reasonable, scientific outlook on life. However, because any Internet users can be free to express any opinion and the information on the network, the network information is the dragons and fishes jumbled together. For college students, the world outlook, outlook on life, values have not yet fully matured, non judgment ability is not strong, identify information capacity is limited, so they are susceptible to strange things to attract and bad information. In the face of all kinds of information online to see things in a blur, complicated, many students confused and disoriented, be at a loss what to do. Values of college students and the value choice is also facing more severe test, showing a double or multiple standards coexist situation of value, value choice and value orientation caused confusion disorder.

The modern convenient communication means and interpersonal indifference. Instant convenient network communication can avoid facing the embarrassment and topic limit exchange; both sides can relax the mood without restraint expression of emotion and thoughts, so it is relatively safe and relaxed, and convenient for online communication. No grades, no difference, only some common identity, exchanges between the two sides are equal, two-way, interactive. College students in the Internet can separate and equal to release and get information, can have any questions you are interested in and the two-way exchange and communication, creative subjectivity of college students get publicity, enhance their concept of modern communication and network communication is indirect, virtual, across the computer screen, the lack of face-to-face communication. In such a virtual world, students experience a virtual emotion achievement and satisfaction on like this for a long time, college students will become increasingly unsuited to the real world, often in the virtual world and to extricate themselves. They encounter problems and setbacks in the real life, tend to seek solace in interpersonal communication in the network, using virtual man-machine communication instead of reality, in the network to avoid direct face contradiction, escaping from the real world, reduce the surrounding people close communication and contact, ignore be close by affection and friendship, thus leading to the actual sealing 
psychology space. If things go on like this it will cause social disorder and bring about interpersonal indifference.

\section{The countermeasures on values of college students under the Internet conditions}

The Internet profoundly affected and changed the college students. These new features are generated in the effects of the world economy, information globalization under, the emergence and existence has its inevitability, the standard cannot simply good and bad to measure. Therefore, college students in the network era values education inevitably shows different characteristics from the traditional period, but also faces difficulties and challenges in the larger. We must face the reality, innovation network moral education pattern, in the light of its general trend, foster strengths and circumvent weaknesses, try to reduce the negative effect of network culture on College Students' values, the network has become the important position and powerful tool of college students value education, it helps students to construct very healthy values

Strengthen the construction of network culture; occupy the Internet position with the excellent educational resources. To vigorously develop the network information resources of socialist which reflect the Chinese culture and Chinese characteristics, and the socialist ideal and faith occupied the position of ideological education, and actively promote the construction of information resources of university students; It can support more news propaganda and cultural institutions and press into the Internet, set up various ideological education of college students in the Internet site, make it become the ideological education of college students communication base; software of Ideological and Political Education Organization experts in the development of college students, closely linked to the ideological work and real life, the connotation of the ideological education in the infiltration of rich and colorful distinctive characteristics of information resources, in order to resist the adverse ideological and cultural erosion on College Students.

Highlight the key content of the value education of college students under network times. In the face of Western ideology of danger and national identity weakening trend, we guide the students to learn foreign outstanding culture and at the same time, we must emphasize the positive role of excellent traditional culture of the Chinese nation, vigorously promote the spirit of the Chinese nation, stimulate their patriotic consciousness and sense of national pride, and consciously resist the negative factors in western culture. The lack of management and supervision of the network world is easy to induce the anarchism and therefore, to strengthen the College Students. Democracy and the rule of law education, improve the democracy and the rule of law concept to make students realize the virtual world and the real world, only we abide by the network moral and legal norms, maintaining the normal order of cyberspace to. Otherwise, no rule of the game will eventually destroy the whole internet. Therefore, college students should consciously abide by the moral and legal norms, anarchism behavior to online, remember oneself social responsibility, do outstanding students to a network era

Strengthen the network information monitoring, creating a good environment of the Internet. The free dissemination of information on Internet, we cannot allow someone to continue, must take the technical monitoring, administrative and other means, as far as possible to control the source of information, to reform from the bottom. One is to establish the information state, with advanced technology, strict monitoring and detection of Internet entrance; filter out harmful false reactionary information two is to execute network real name system, the real-time data monitoring technology, the network technology inspection personnel tracking interception technology on Internet information, once found adverse development of college students information they should immediately removed it, thus can prevent the adverse information access and dissemination and 
create a good atmosphere for students.

\section{Conclusions}

In a word, the mainstream values of the contemporary college students are healthy and upward, positive enterprising, but there are also many cognitive biases. The emergence of these problems is not accidental, it has its profound social background and therefore, university life value education and guide is a system engineering, it needs to mobilize the enthusiasm of the government, society, schools and other areas, work together to do a good job, only in this way can effectively help students to establish the correct values, to realize the value of life.

\section{Acknowledgements}

This is the education science, Hunan province, the "Thirteen-Five" plan 2016 project "MOOC times marketing professional teaching reform mode in higher vocational colleges" (project number: XJK016CZY033) of initial results.

\section{References}

[1] L. Bourdeau, J. C. Chebat, C. Couturier, Internet consumer value of university students: E-mail-vs.-Web users, Journal of Retailing and Consumer Services, 9 (2002) 61-69.

[2] H. peng, C. C. Tsai, University students' self - efficacy and their attitudes toward the Internet: the role of students' perceptions of the Internet, Educational Studies, 32 (2006) 73-86.

[3] P. M. Odell, K. O. Korgen, P. Schumacher, Internet Use Among Female and Male College Students, CyberPsychology \& Behavior, 3 (2004) 855-862.

[4] N. Li, G. Kirkup, Gender and cultural differences in Internet use: A study of China and the UK, Computers \& Education, 48 (2007) 301-317.

[5] Y. T. Wu, Dr. C.-C. Tsai, University Students' Internet Attitudes and Internet Self-Efficacy: AStudy at Three Universities in Taiwan, CyberPsychology \& Behavior, 9(4) (2006) 441-450..

[6] N. S. A Karim, Exploring the relationship between Internet ethics in university students and the big five model of personality, Computers \& Education, 53 (2009) 86-93.

[7] X. Ni, H. Yan, S. Chen, Z. Liu, Factors Influencing Internet Addiction in a Sample of Freshmen University Students in China, CyberPsychology \& Behavior, 12 (2009) 327-330. 